Fourth International Conference on Sustainable Construction Materials and Technologies http://www.claisse.info/Proceedings.htm

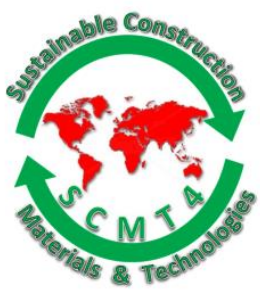

SCMT4

Las Vegas, USA, August 7-11, 2016

\title{
Techniques for Improving Lives by Green Low Income Housing
}

\author{
Syed Faiz Ahmad ${ }^{1}$ \\ ${ }^{1}$ Chief Structural Engineer; Saudi Oger Ltd; P.O. Box: 1449; Riyadh-11431; Saudi Arabia; \\ Email: <syedfaiz23@hotmail.com>
}

\begin{abstract}
The concept of Green housing too often is thought to be things meant for some institutionalized facilities in upscale locations of a city or a town. It is seldom thought to be applicable to low-cost housing for the low-income populace. As such Green affordable housing for the low income communities in the developing countries till to-date remains a far-fetched dream. The reason is very simple as most high performance green building materials and techniques are too expensive and beyond the reach of the low income communities in the developing countries. In the developing country settings where a vast majority of them lack even the basic services, the green building approach to tackling the climate change is simply an uphill task and unaffordable also.

There is therefore an urgent need for a meaningful research into the area of low-cost green building innovative materials and techniques so as to make it available and affordable to the vast majority of the low income populace throughout the world. This research paper focuses on the subject of application of lowcost innovative green building materials and technique for improving lives of the inhabitants in low income housing.

This research paper presents alternative \& innovative yet low-cost building materials \& techniques that have been identified and whose applications in low income housing can help provide a reasonable level of comfort inside during all seasons. Such materials and techniques are easy to apply and are affordable also. Moreover, such innovative low-cost green building materials and techniques provide for sustainable features and are long-life too. A case study has also been presented with the application of innovative lowcost green building materials and techniques in model low income housing.
\end{abstract}

\section{LOW COST HOUSING - A SERIOUS GLOBAL ISSUE}

The United Nations estimates that there are a billion plus poor people in the World, 750 million of who live in urban areas without adequate shelters and basic services. Moreover, according to another estimates by the United Nations, World's developing nations need more than 740 million houses now. This means if we built 100,000 houses a day for 20 years, we would still be 20 years behind. So, it clearly implies that we need to do something different if we are to ensure that all human beings can live with dignity. We therefore need low cost building materials, efficient construction technologies, and smarter construction processes. It is encouraging to note that housing sector in the developing countries is an area where much research has 
been conducted in recent years. As a result, a variety of innovative $\&$ alternative prescriptions have been suggested and accepted for trial \& testing at pilot scheme levels [Ahmad 2010].

Since the adoption of "Universal Declaration of Human Rights", at the 1996 UN Habitat Conference, "adequate shelter for all" has been recognized as a basic human need. All governments thus have responsibilities to take appropriate measures in order to promote, protect, and ensure proper realization of provision of adequate housing for its citizens.

Case of South Asia. South Asia is home to almost one-third of the World's inhabitants, two-thirds of whom live in inadequate or makeshift shelters. The failure to address the pressing need for affordable housing by both public and private institutions, is not only due to neglect but also due to a failure of the Engineering community to come up with appropriate engineering solutions and delivery strategies [Javed 2004].

Case of Pakistan. Providing affordable housing to low-income people has remained a challenge in Pakistan since long. Although some efforts have been made in the past, both in the public and private sectors, to mitigate the same yet the issue seems to be still out of hand. The phenomenal increase in the cost of land together with rising prices of building materials and increased labor cost, all of them are in fact making the goal of the low-income housing unattainable.

Major cities in Pakistan continue to face the problem of large-scale urbanization and the menacing issue of illegal squatter settlements or slums - also known in the local dialects as Katchi Abadies. Karachi is the largest city of Pakistan with an estimated population close to 20 million. According to a study nearly half of the Karachi metrópolis consists of squatter settlements or Katchi Abadies. The situation in other metrópolis in Pakistan like Lahore, Rawalpindi, Peshawar, Quetta is relatively better but not much different [Ahmad 2009].

Housing Backlog in Pakistan. According to sources in the Ministry of Housing (National Housing Policy-2001), in Pakistan a backlog of some nine million housing units have already accumulated. About 300,000 formally built units are added annually with most concentrations in the urban areas. However this is not enough to meet the requirements as such the backlog continues to soar [Ahmad 2010].

\section{GREEN BUILDING DEFINITION}

Although there is no single definition of a Green Building, however in simple terms a Green Building can be defined as a high-performing building designed, built, operated and disposed of in a resource-efficient manner with the aim to minimize the overall negative impact on the built environment, human health and the natural environment. Green building is also known as a sustainable or high performance building. Green buildings are designed to reduce the overall impact of the built environment on human health and the natural environment by:

- Efficiently using energy, water, and other resources

- Protecting occupant health and improving employee productivity

- Reducing waste, pollution and environmental degradation

For example, Green Buildings may incorporate sustainable materials in their construction (e.g., reused, recycled-content, or made from renewable resources); create healthy indoor environments with minimal pollutants (e.g., reduced product emissions); and/or feature landscaping that reduces water usage - that is, by using native plants that survive without extra watering [USEPA 2011]. 
This means it is aimed to minimize the overall negative impact on the built environment, human health and the natural environment. Some key element of Green Building features include but are not limited to: choice of site and orientation, efficient use of building materials and resources, indoor environment quality and innovation. Green Building is the practice of creating structures and using processes that are environmentally responsible and resource-efficient throughout a building's life-cycle from siting to design, construction, operation, maintenance, renovation and deconstruction. This practice expands and complements the classical building design concerns of economy, utility, durability, and comfort. Green Building is also known as sustainable or high performance building [Clayton 2008].

\section{NEED OF A LOW-INCOME GREEN HOUSING}

The concept of Green housing too often is thought to be things meant for some institutionalized facilities in upscale locations of a city or a town. It is seldom thought to be applicable to low-cost housing for the low-income populace. As such Green affordable housing for the low income communities in the developing countries till to-date remains a far-fetched dream. The reason is very simple as most high performance green building materials and techniques are too expensive and beyond the reach of the low income communities in the developing countries.

The term "Green Building" is often used interchangeably with the term "Sustainable Building", "HighPerformance Building" and "Environmentally Responsible Building". On the other hand, the term "LowIncome Housing" is often used interchangeably with the term "Affordable Housing". It is mostly used to describe single-family or multi-family dwellings that have purchase prices or rental payments affordable to low-to-moderate income individuals and/or families. For most people "Green Building" and "Low-Income Housing" are not considered compatible. However, for arguments sake at least, if the term "Affordable or Low-Income Housing" is used to describe "Sustainable Affordability" of single-family or multiple-family dwellings for lower-income individual/family then Green Building becomes a perfect companion [TFESSD 2011].

How to Make a Green Low-Income House. While there is a long list of things that can be done make a house Green, however the following tips are all the more important towards sustainability of a low-income house.

- Design for use of máximum natural daylighting

- Use natural ventilation to improve indoor comfort

- Waste material and/or recycled locally available building materials for better thermal mass

- Cut wáter consumption by installing water-efficient fixtures and recycle waste water for irrigation

- Use low-cost toilets and reduce pollution

Maximum Natural Daylighting. In order to understand how to control the Sun, it is important to understand the Sun's astronomical path in relation to Earth. The Sun is highest in the sky on the Summer Solstice - 21, 22 December in Southern Hemisphere and 20, 21 June in the Northern Hemisphere. The apparent position at which the Sun rises and sets changes seasonally. Building form and orientation is very important in controlling the Sun. It is also important to understand the interactions between window heights, fins, and overhangs.

Making Indoors Comfortable by Natural Means. Sun, land, and water interact in complicated ways throughout each day and througout the year, and the result is what we commonly refer to as weather. These interactions produce daily as well as seasonal temperature, humidity, and wind patterns that can vary substantially betwen locations in close geographic proximity. 
Climate-responsive design is a strategy that seeks to take advantage of the positive climate attributes of a particular location, while minimizing the effects of attributes that may impair comfort or increase energy requirements. Climate-responsive design seeks to create inherently comfortable buildings that require mínimum energy input - with no narural ventilation and daylight in building designs.

It is said that thermal comfort is achieved when 80 percent of sedentary or slightly active persons find the environment thermally acceptable. To improve thermal comfort in buildings the following should be ensured: 1)Understand a climate's barriers to confort, 2) Use building materials that help improve themal confort, 3)Allow sunlight, air/wind to enter the building naturally

Ventilation is the intentional movement of air from outside a building to the inside. Natural ventilation is the process of supplying and removing air through an indoor space by natural means. There are two types of natural ventilation occurring in buildings: 1)Wind Driven Ventilation, 2)Stack Ventilation

Using Wind movement or Thermal (Stack) effects to ventilate a building through its doors, windows, ventilators, or other openings is cost effective as compared to using mechanical fans. Natural ventilation can serve two functions that would otherwise be provided by mechanical system: 1)Space cooling for confort, 2)Ventilation for indoor air quality

For air to move into and out of a building, a pressure difference between the inside and outside of the building is required. And, the pressure difference is caused by: 1)Wind or Wind effect, 2) Stack or Chimney effect that depends on the difference in air density due to temperature difference between indoor and outdoor, 3)Combination of both Wind and Stack effects

Wind-Catcher - an Effective Means of Wind Driven Ventilation. Wind driven ventilation provides comforts to occupants using the least amount of resources. It also takes advantage of the natural passage of air without the need for high energy consuming equipment.

Wind Catchers are one of the age-old means to achieve natural wind driven ventilation and elevate the indoor comfort level. It is a time-tested traditional Persian architectural device used for many centuries to create natural ventilation in buildings. Wind Catchers come in various designs such as the Uni-Directional, Bi-Directional, and Multi-Directional types.

Wind Catcher is able to effectively aid wind driven ventilation by directing air in and out of buildings. It has the following merits [Azmi 2005, Shady et al 2009]: 1)It provides increased occupant satisfaction and confort, 2)Occupants remain healthier and have increased productivity, 3)It ensures reduced energy use and greenhouse gas enmissions

Thermal Mass to Improve Comfort by Means of Low-Cost Indigenous Materials. Thermal Mass describes a building material's ability to store thermal energy and delay heat transfer through a building component. Thermal mass reduces the daily tmperature swing inside a building. A building in a very hot or cold climate using thermal mass will usually have lower energy consumption for HVAC versus a building using low-mass building materials. The main thermal mass properties are: specific heat $(\mathrm{C})$, density $(\mathrm{P})$, thermal conductivity $(\mathrm{K})$, thermal resistivity $(\mathrm{R})$, and heat capacity $(\mathrm{B})$

Cut Water Consumption and Rcycle Water for Internal Irrigation. A smart way to ensure that the water of the occupants remains low is to install water-efficient fixtures and toilets. Unlike old toilets that required 18 to 20 liters of water in every flush, new toilets use only 6 liters per flush. In another way, water can be recycled also. For this purpose water from kitchen sink and wash basins can be diverted to and collected in a tank for later use. The waste water can be used for gardening, for irrigation of house-hold vegetable garden and for washing \& laundry also. 
Use Low-Cost Efficient Toilets and Reduce Pollution. Low-cost toilets can be built on self-help basis. Such toilets are healthy and also reduce pollution. The waste can be recycled and used as manure \& fertilizer in the house-hold vegetable gardens. Twin-pit pour flush latrine is one such example as shown in figure 1. Having two pits is certainly an advantage as when the first pit gets filled up, the flow of excreta has to be diverted to the second pit. In this design, two leach pits are connected to one single pour-flush toilet. Twin-pit toilets have a high convenience - when emptying one pit, people use second pit. Estimated cost of 1 toilet shall be approximately US \$ 75 [Prema 2014, UNICEF 2010].

Bio-Gas linked toilet is yet another efficient option. This design - as shown in figure 2 - offers support to convert waste matter to Bio-Gas, a non-conventional energy source. The fuel generated can be used as local source for electricity, heat and light. Moreover, the waste can be composted to Bio-manure which increases productivity and catalyses soil conservation. Estimated cost of 1 toilet shall be approximately US \$50 [Prema 2014, UNICEF 2010].
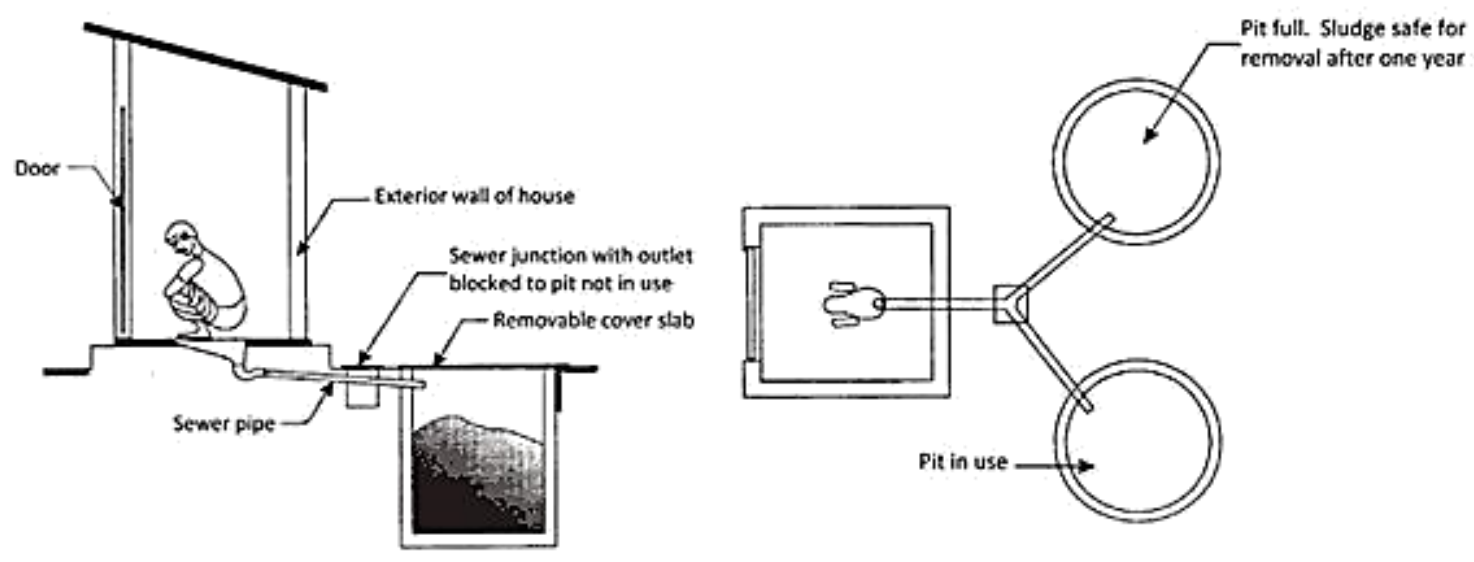

Figure 1. Twin-Pit Pour Low-Cost Flush Latrine [Prema 2014]

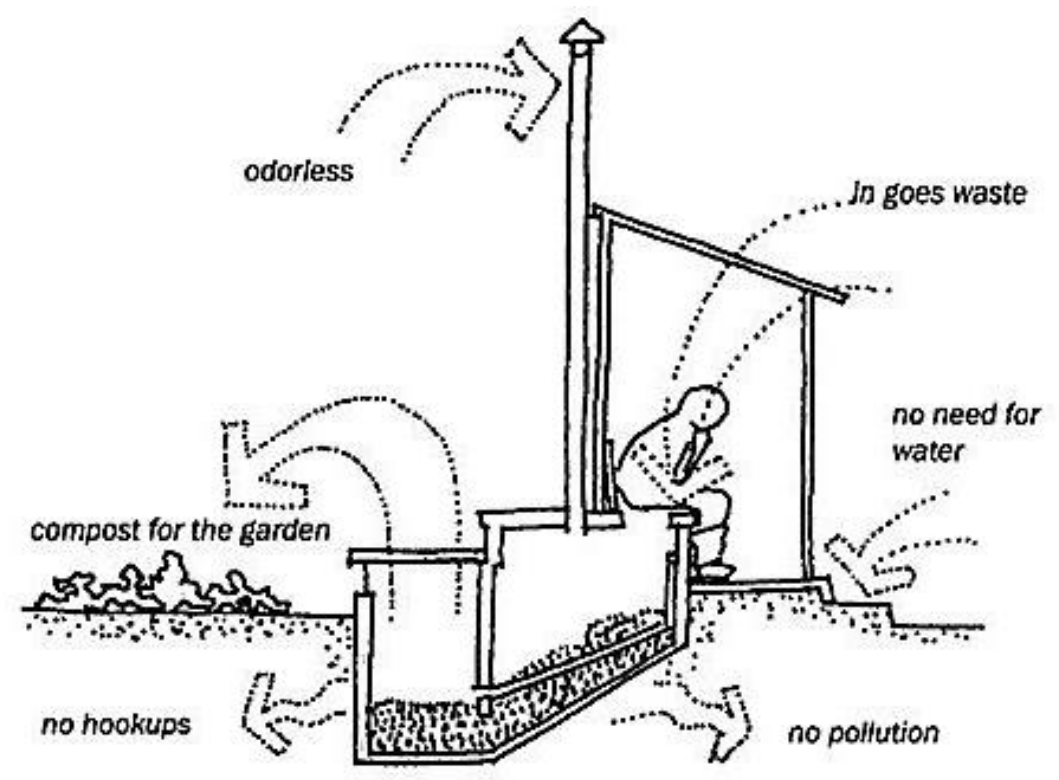

Figure 2. Bio-Gas Linked Low-Cost Toilet [Prema 2014] 

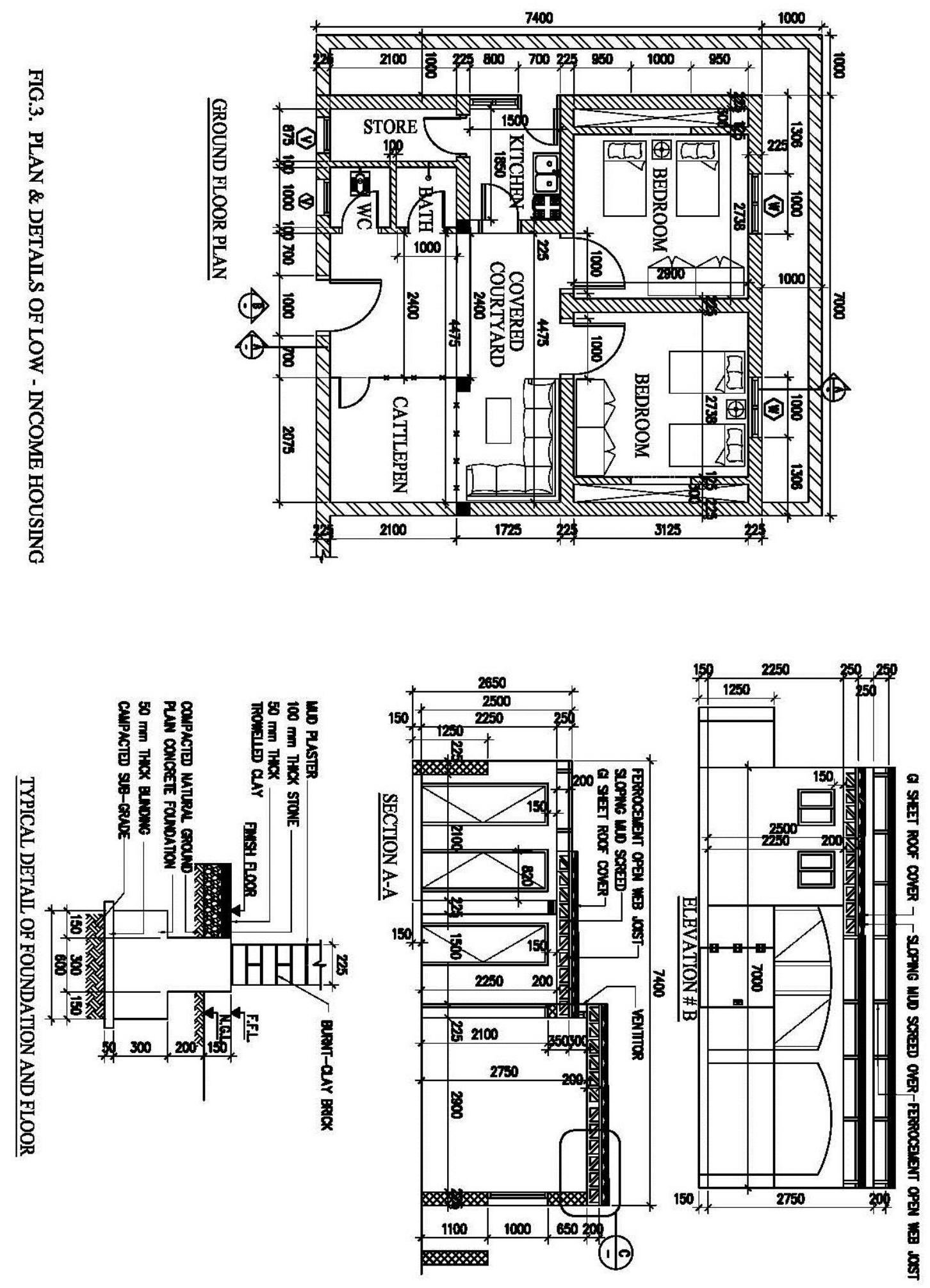

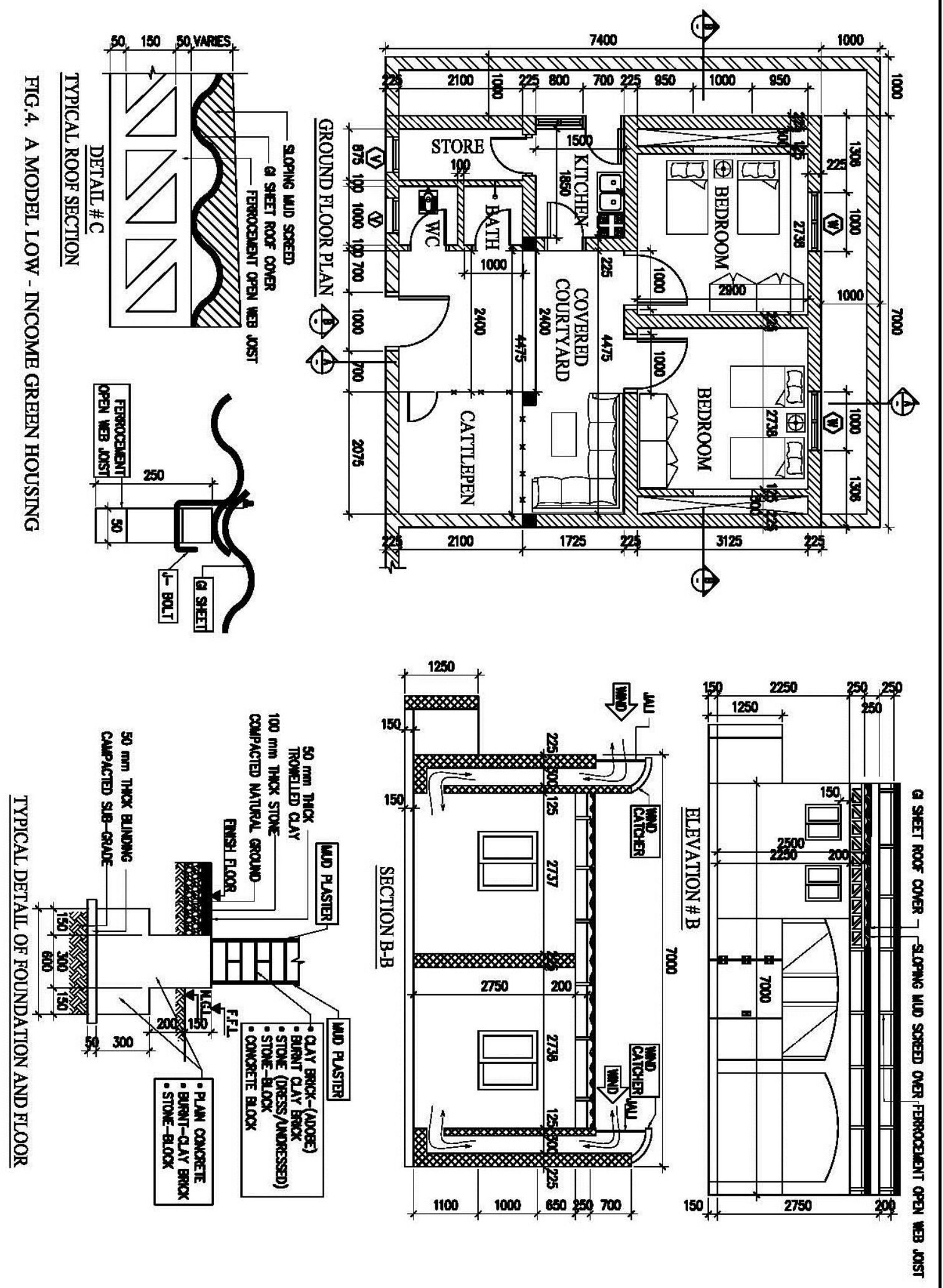


\section{MODEL LOW-INCOME GREEN HOUSE}

A model low-income green house is shown in Fig.3 and in figure 4. (shown in above) wherein all kinds of low-cost indigenous materials \& innovative techniques have been applied on a typical low-income house to make it Green. Components of Green Materials \& Innovative Techniques - from foundation to roof - are detailed \& described as follows:

1) Foundation. Depending upon soil condition and depth of ground water table, it can be constructed by using sundried clay brick (adobe), burnt-cay brick, Stones (dressed or undressed), stone-block or simply by using plain concrete blocks.

2) Flooring. It can be sun-dried clay tiles topped with mud plaster or simply trowelled clay.

3) Load Bearing Walls. Load bearing walls can be constructed by using sundried clay brick (adobe), burntcay brick, Stones (dressed or undressed), stone-block or simply plain concrete blocks. The load-bearing walls can be plastered with mud or mud reinforced with thatches or grain fibers. Cow dung can also be applied both on the interior and exterior surfaces of load-bearing walls.

4) Roof. Green roof can be formed from a plenty of options. It can make use of wooden or steel joists in combination with sun-dried clay tiles, burnt-clay tiles or plain concrete tiles. It can also make use of innovative alternatives like barrel-shell plank, open-web joist in combination with GI sheet, etc. The roof can be topped with sloping mud screed to keep the inside temperature cool.

5) Wind Catcher. Wind Catchers can be very easily built using sundried clay brick (adobe), burnt-cay brick, Stones (dressed or undressed), stone-block or simply plain concrete blocks, as is shown in figure 3 $\&$ figure 4 .

\section{CONCLUSION}

The following general conclusions can be drawn from the study provided in the paper:

- Green housing too often is thought to be things meant for some institutionalized facilities in upscale locations of a city or a town. It is seldom thought to be applicable to low-cost housing for the lowincome populace.

- Green affordable housing for the low income communities in the developing countries till to-date remains a far-fetched dream. The reason is very simple as most high performance green building materials and techniques are too expensive and beyond the reach of the low income communities in the developing countries.

- This research paper presents alternative $\&$ innovative yet low-cost building materials $\&$ techniques that have been identified and whose applications in low income housing can help provide a reasonable level of comfort inside - during all seasons.

- Low-Income Housing thus can also be made Green with the use of indigenous building materials and by application of innovative techniques.

- Wind-Catcher is an effective and low-cost tool in improving comfort level inside. This is a centuries old traditional time-tested Iranian architectural device for keeping inside cool during hot summer.

- With little ingenuity and adoption of simple techniques $\&$ practices, a low-cost house can easily be made green - without or with a little extra cost. 


\section{REFERENCES}

A. Azami (2005), "Badgir in Traditional Iranian Architecture." Proceeding of International Conference on Passive and Low Energy Cooling; May 2005; Santorini-Greece.

Ahmad, S. F. (2009), "Precast Ferrocement Barrel Shell Planks as Low Cost Roof." Proceeding of ISEC-5 Conference; 21-27 September 2009; Las Vegas, NV, USA

Ahmad, S. Faiz. (2010), "Lightweight Ferrocement Open Web Joists as Low Cost Roof." Proceeding of ICSA-2010 Conference; 21-23 July 2010; Guimaraes-Portugal

Ahmad, S. F. (2011), "Precast Stone-Block as Low Cost Load-Bearing Walls.” Proceeding of ISEC-6 Conference; 21-26 June 2011; Zurich, Switzerland.

Clayton, B. (2008), "Greening Your Home: Sustainable Options for Every System in Your House." McGraw-Hill, New York, USA

Javed, S. (2004), “Technological Challenges to Implementing an Affordable Housing Policy.” Sarid Journal, USA.

Prema, N. A. (2014), "10 Toilet Designs that can actually work in Rural India." The Alternative.N, India Shady et al (2009), "Designing the Malqaf for Summer Cooling in Low-Rise Housing, an Experimental Study.” Proceeding of 26th Conference on Passive and Low Energy Architecture; 22-24 June 2009; Quebec City-Canada.

TFESSD. (2011), “Addressing Climate Change with Low Cost Green Housing. " A Publication of Trust Fund for Environmentally and Socially Sustainable Development, Norway.

UNICEF (2010), "Design and Construction Manual for Water Supply and Sanitary Facilities in Primary Schools." Ministry of Health, Education and Water \& Energy in Collaboration with UNICEF; Ethiopia. U.S. Environmental Protection Agency-USEPA (2011), "Energy Efficiency in Affordable Housing: A Guide to Developing and Implementing Greenhouse Gas Reduction Program." Retrieved 21, USA Vivian, H. (2008), "Going Green: Hints \& Tips to Reduce your Carbon Footprint.” Abbeydale Press, UK. Zalejska et al (2011), “Low-Energy Residential Buildings, Evaluation from Investor and Tenant Perspectives." KTH Royal Institute of Technology, Denmark. 